\title{
Meningkatkan Percaya Diri Siswa melalui Teknik Cognitive Defusion
}

\author{
Wahyu Nanda Eka Saputra, Hardi Prasetiawan \\ Program Studi Bimbingan dan Konseling, Fakultas Keguruan dan Ilmu Pendidikan, \\ Universitas Ahmad Dahlan, Jl. Pramuka No. 42, Yogyakarta, Daerah Istimewa Yogyakarta, Indonesia 55161 \\ E-mail: wahyu.saputra@bk.uad.ac.id
}

Artikel diterima: 23 Januari 2018; direvisi 21 Maret 2018; disetujui 27 Maret 2018

\begin{abstract}
This study aims to identify the effectiveness of cognitive defusion technique to increase students' self confidence. This study used a pre-experimental design with one group pre-test post-test design. Subject in this study were six vocational high school student which have low self-confidence. The instrument used is self-confidence scale. To analyze the subjects' self confidence after receiving cognitive defusion technique, we use the wilcoxon sign test. The results confirm that students' confidence level score were increase after being treat using cognitive defusion technique. It can be concluded that cognitive defusion technique are effective for improving students' self-confidence.
\end{abstract}

Keywords: self-confidence; cognitive defusion technique; vocational high school

\begin{abstract}
Abstrak: Tujuan penelitian ini adalah untuk mengetahui keefektifan teknik cognitive defusion untuk meningkatkan percaya diri siswa. Penelitian ini menggunakan pre-experimental design dengan rancangan one group pre-test post-test design. Subjek dalam penelitian ini melibatkan enam siswa Sekolah Menengah Kejuruan (SMK) di kota Yogyakarta yang memiliki tingkat percaya diri rendah. Instrumen yang digunakan adalah skala percaya diri. Analisis yang digunakan untuk menguji perbedaan percaya diri sebelum dan sesudah diberikan perlakuan konseling teknik cognitive defusion adalah uji jenjang bertanda Wilcoxon. Hasil menunjukkan bahwa terdapat kenaikan skor tingkat percaya diri siswa setelah diberikan perlakuan berupa konseling teknik cognitive defusion. Dapat disimpulkan bahwa teknik cognitive defusion efektif untuk meningkatkan tingkat percaya diri siswa.
\end{abstract}

Kata kunci: percaya diri; teknik cognitive defusion; SMK

Percaya diri menjadi aspek yang penting dalam perkembangan siswa di sekolah (Amilin, 2016). Kepercayaan diri memberikan kemampuan individu untuk mengatasi tantangan baru, meyakini diri sendiri dalam situasi sulit, melewati batasan yang menghambat, menyelesaikan hal yang belum pernah dilakukan, mengeluarkan bakat serta kemampuan sepenuhnya, dan tidak mengkhawatirkan kegagalan (Perry, 2005). Berbagai aktifitas sekolah yang melibatkan percaya diri siswa antara lain berpendapat dalam diskusi, bertanya pada guru ketika mengalami kesulitan, dan mengutarakan gagasan di depan umum. Jika siswa tidak menampilkan percaya diri yang tinggi, tentu akan berpengaruh terhadap performa akademik mereka di sekolah (Gatz \& Kelly, 2017).

Berbagai penelitian di Indonesia telah menunjukkan bahwa permasalahan percaya diri masih dialami oleh siswa. Sebuah hasil penelitian tentang percaya diri menunjukkan bahwa 2,17\% sampel memiliki percaya diri sangat tinggi, 22,46\% sampel memiliki percaya diri tinggi, 57,97\% sampel memiliki percaya diri sedang, 13,77\% sampel memiliki percaya diri rendah, dan 3,62\% kategori sangat rendah (Suhardita, 2011). Penelitian lain tentang profil kepercayaan diri siswa menunjukkan hasil presentase skor $0,70 \%$ siswa berada pada kategori rendah, 78,47\% siswa berada pada kategori 
sedang dan 20,83\% siswa berada pada kategori tinggi (Mastur, Sugiharto, \& Sukiman, 2012). Berbagai penelitian tersebut menunjukkan bahwa rendahnya percaya diri siswa merupakan masalah yang ada di sekolah, termasuk siswa SMK di Yogyakarta. Sebuah penelitian mengenai percaya diri di Sekolah Menengah Atas (SMA) di Kodya Yogyakarta menyatakan bahwa siswa memiliki permasalahan dengan rendahnya percaya diri (Afiatin \& Martaniah, 1998). Beberapa contoh perilaku siswa yang menunjukan rasa tidak percaya diri adalah suka mencontek pekerjaan orang lain, tidak bersemangat ketika mengikuti pelajaran, takut berbicara di depan kelas dan keinginan berprestasinya kurang.

Dampak akademik rendahnya percaya diri siswa meliputi menurunnya performa akademik, motivasi berprestasi, dan performa akademik (Stankov, Morony, \& Lee, 2014). Pertama, tingkat percaya diri siswa yang rendah memiliki dampak negatif terhadap performa akademik (Tavani \& Losh, 2003). Tingkat percaya diri yang tinggi, akan menyumbang tingginya performa akademik siswa. Sebaliknya, rendahnya percaya diri, akan mengakibatkan rendahnya performa akademik siswa. Kedua, percaya diri yang rendah memiliki pengaruh terhadap motivasi berprestasi, hasil penelitian di SMA Negeri 1 Salatiga menunjukkan bahwa semakin tinggi kepercayaan diri maka akan semakin tinggi pula motivasi berprestasi (Tatuh, 2012). Ketiga, tingkat percaya diri siswa yang rendah memiliki dampak negatif terhadap prestasi akademik (Al-Hebaish, 2012). Tingkat percaya diri yang tinggi, akan menyumbang tingginya prestasi akademik siswa. Sebaliknya rendahnya percaya diri, akan menyumbang rendahnya prestasi akademik siswa.

Dampak non-akademik terkait rendahnya percaya diri siswa meliputi meningkatnya kecemasan dalam melakukan komunikasi interpersonal dan berbicara di depan umum. Pertama, tingkat percaya diri yang rendah juga memiliki dampak pada kecemasan siswa dalam melakukan komunikasi interpersonal (Siska, Sudardjo, \& Purnamaningsih, 2003). Kepercayaan diri memberikan sumbangan efektif sebesar 52,6\% terhadap kecemasan komunikasi interpersonal, sementara sisanya 47,4\% ditentukan oleh faktor lain di luar kepercayaan diri, seperti keterampilan berkomunikasi, situasi, pengalaman kegagalan atau kesuksesan dalam komunikasi interpersonal, dan predisposisi genetik. Kedua, percaya diri memiliki korelasi dengan kecemasan berbicara di depan umum (Wahyuni, 2014). Individu yang memiliki percaya diri rendah akan berdampak pada semakin cemasnya individu dalam berbicara di depan umum. Sebaliknya, jika individu semakin percaya diri, maka akan berdampak pada semakin rendahnya kecemasan seseorang berbicara di depan umum. Ketiga, body image siswa juga akan terpengaruh, hal ini dikarenakan percaya diri punya hubungan yang signifikan dengan body image (Ifdil, Denich, \& Ilyas, 2017)

Percaya diri yang rendah pada pelajar SMK di Yogyakarta perlu diatasi. Selama ini beberapa penelitian menunjukkan bahwa percaya diri dapat ditingkatkan dengan konseling kelompok (Imro'atun, 2017), self-instruction (Fiorentika, Santoso, \& Simon, 2016), skill based training (Proude, Conigrave, \& Haber, 2006), dll. Salah satu pendekatan konseling lain yang bisa diterapkan untuk meningkatkan percaya diri siswa SMK adalah Acceptance and Commitment Therapy (ACT). $A C T$ adalah model baru konseling singkat yang merupakan pendekatan yang sangat mapan (Strosahl, Robinson, \& Gustavsson, 2012). ACT dikenal sebagai wajah baru dari Cognitive Behavioral Therapy (CBT) (Forman, Herbert, Moitra, Yeomans, \& Geller, 2007; Fung, 2015; Yovel, 2009). ACT tidak berupaya mengubah konteks kognisi untuk mempromosikan perubahan perilaku (Ruiz, 2012), akan tetapi $A C T$ berfokus pada perilaku individu dan konteks terjadinya (Bach \& Moran, 2008). $A C T$ mendorong pengakuan dan penerimaan terhadap pikiran dan emosi negatif serta menghambat penghindaran terhadap pengalaman (Markanday et al., 2012). Harapannya setelah konseli berhasil mengurangi pikiran dan emosi yang tidak diinginkan, konseli akan lebih mudah untuk fokus pada rencana dan tujuan yang realistis. Komitmen yang ditunjukkan dengan tindakan nyata adalah domain $A C T$ yang sangat penting dalam pelaksanaan intervensi (Bach \& Moran, 2008).

Secara spesifik, teknik $A C T$ yang dapat digunakan untuk meningkatkan percaya diri siswa SMK adalah teknik cognitive defusion yang sering dipakai dalam latar dimana konseli terlibat dalam masalah pribadi seperti pikiran diri negatif yang sangat mendalam (Masuda, Feinstein, Wendell, \& Sheehan, 2010). Teknik cognitive defusion kurang lebih dikonseptualisasikan sebagai pengubahan 
makna kata-kata dan fungsi pengaturan perilaku dari masalah pribadi yang dialami tanpa mengubah bentuk, frekuensi, dan situasi yang sensitif pada diri mereka (Masuda, Hayes, Sackett, \& Twohig, 2004). Setelah dilaksanakan intervensi konseling dengan menggunakan teknik cognitive defusion, konseli diharapkan sampai pada pemahaman bahwa pikiran negatif yang menyebabkan rendahnya percaya diri hanyalah sebuah suara dalam pikiran dan tidak perlu untuk didengarkan dan dilaksanakan.

Di indonesia sendiri belum banyak dilakukan penelitian yang menguji keefektifan teknik cognitive defusion untuk meningkatkan percaya diri siswa. Terlebih lagi, teknik ini merupakan merupakan teknik dari pendekatan baru dalam konseling, yaitu $A C T$ yang merupakan wajah baru dari $C B T$. Berdasarkan pemaparan di atas, penelitian ini akan menguji keefektifan konseling teknik cognitive defusion dalam meningkatkan percaya diri siswa SMK.

\section{METODE}

Penelitian ini merupakan penelitian pre-experimental design karena peneliti tidak memakai variabel kontrol dan sampel tidak dipilih secara acak. Bentuk rancangan pre-experimental design ini memakai one group pre-test post-test design, sehingga hasil penelitian ini akan menunjukkan tingkat percaya diri siswa sebelum dan sesudah diberikan konseling dengan teknik cognitive defusion. Subjek dalam penelitian ini adalah enam siswa SMK Muhammadiyah 3 Yogyakarta yang memiliki tingkat percaya diri rendah berdasarkan pengukuran dengan instrumen skala percaya diri.

Skala percaya diri dikembangkan menggunakan sintesis dari teori yang dikembangkan oleh beberapa ahli (Hakim, 2002; Hankin, 2005; Lie, 2008). Skala percaya diri terdiri dari lima indikator, yaitu: (1) menyesuaikan diri dan berkomunikasi di berbagai situasi; (2) memiliki kemampuan bersosialisasi; (3) memiliki pengalaman yang menempa mental menjadi kuat terhadap cobaan; (4) tenang di dalam mengerjakan sesuatu; (5) menetralisir ketegangan yang muncul; dan (6) selalu bereaksi dan bertindak positif di dalam menghadapi berbagai situasi. Setelah diberikan konseling teknik cognitive defusion, dilakukan pengukuran kembali dengan menggunakan skala percaya diri agar diketahui apakah terdapat perbedaan skor percaya diri sebelum dan sesudah diberikan konseling teknik cognitive defusion.

Analisis kuantitatif menggunakan teknik analisis statistik non-parametric. Analisis yang digunakan untuk menguji dalam penelitian ini adalah uji jenjang bertanda Wilcoxon. Penghitungan uji statistik dengan menggunakan SPSS 21. Hasil analisis data akan menunjukkan perbedaan tingkat percaya diri siswa antara sebelum dan sesudah diberikan intervensi teknik cognitive defusion.

\section{HASIL}

Hasil uji efektifitas teknik cognitive defusion untuk meningkatkan percaya diri siswa disajikan dalam tabel 1. Hasil uji pada tabel 1 kemudian dianalisis menggunakan uji jenjang bertanda Wilcoxon menggunakan SPSS 21 sehingga dapat ditemukan nilai-nilai yang diperlukan untuk menghitung uji jenjang bertanda Wilcoxon. Output penghitungan dengan program SPSS disajikan pada tabel 2.

Tabel 1 Hasil Uji Efektifitas Teknik Cognitive Defusion untuk Meningkatkan Percaya Diri Siswa

\begin{tabular}{cccccc}
\hline No & Inisial Subjek & Pre-test & Kategori & Post-test & Kategori \\
\hline 1 & RDP 13 & 79 & Rendah & 88 & Sedang \\
2 & RDP 18 & 72 & Rendah & 85 & Sedang \\
3 & RDP 19 & 76 & Rendah & 86 & Sedang \\
4 & RDP 27 & 69 & Rendah & 85 & Sedang \\
5 & RDP 32 & 84 & Rendah & 92 & Sedang \\
6 & RDP 76 & 80 & Rendah & 91 & Sedang \\
\hline
\end{tabular}


Tabel 2 Rank Uji Jenjang Bertanda Wilcoxon

\begin{tabular}{llccc}
\hline & & N & Mean Rank & Sum of Ranks \\
\hline Post-test - Pre-test & Negative Ranks & $0^{\mathrm{a}}$ & .00 & .00 \\
& Positive Ranks & $6^{\mathrm{b}}$ & 3.50 & 21.00 \\
& Ties & $0^{\mathrm{c}}$ & & \\
& Total & 6 & & \\
\hline
\end{tabular}

Keterangan:

a : Post-test $<$ Pre-test

$\mathrm{b}:$ Post-test $>$ Pre-test

c : Post-test $=$ Pre-test

Tabel 3 Test Statistic Uji Jenjang Bertanda Wilcoxon

\begin{tabular}{ll}
\hline \multicolumn{1}{c}{ Test Statistics $^{\mathrm{b}}$} \\
\hline & Post-test - Pre-test $^{\text {Z }}$ \\
Z & $-2.201^{\mathrm{a}}$ \\
Asymp. Sig. (2-tailed) & .028 \\
\hline
\end{tabular}

Keterangan:

a : Based on negative ranks

b : Wilcoxon Signed Ranks Test

Berdasarkan tabel 2 dapat diketahui bahwa negative ranks berjumlah 0, yang bermakna tidak ada penurunan tingkat percaya diri antara sebelum dan sesudah diberikan perlakuan berupa model konseling teknik cognitive defusion. Selanjutnya, positive ranks berjumlah 6 , yang bermakna bahwa enam subjek penelitian mengalami kenaikan tingkat percaya diri sebelum dan sesudah diberikan perlakuan berupa model konseling teknik cognitive defusion. Sedangkan ties berjumlah 0, yang bermakna tidak ada subjek penelitian yang skor tingkat percaya dirinya menetap antara sebelum dan sesudah diberikan perlakuan konseling teknik cognitive defusion. Berdasarkan tabel 2 juga didapatkan hasil bahwa skor kenaikan rata-rata pada setiap subjek penelitian adalah 3,5 poin.

Hasil uji Jenjang Bertanda Wilcoxon yang disajikan pada tabel 3 menunjukkan bahwa nilai $\mathrm{Z}$ hitung adalah $-2,201$, sedangkan nilai $\mathrm{Z}$ tabel diperoleh dari tabel $\mathrm{Z}$ dengan alpha $5 \%$ nilainya -0,986 (tanda negatif disesuikan saja tergantung output dari $Z$ hitung). Sedangkan pada nilai Asymp. Sig (2-tailed) diperoleh 0,028. Karena $Z$ hitung $>Z$ tabel yaitu $-2,201>-0,986$ atau nilai sig 0,028 $<0,05$ sesuai dengan pengujian statistik yang kita gunakan maka dapat diinterpretasikan bahwa terdapat kenaikan skor tingkat percaya diri siswa antara sebelum dan sesudah diberikan perlakuan berupa konseling teknik cognitive defusion.

\section{PEMBAHASAN}

Uji eksperimen menunjukkan bahwa konseling teknik cognitive defusion dapat meningkatkan percaya diri siswa. Individu mampu untuk mengubah konteksnya dalam berpikir negatif sehingga mereka dapat mengabaikan pikiran negatif yang ada pada diri mereka daripada mendengarkan dan melakukannya (Hayes, Luoma, Bond, Masuda, \& Lillis, 2006). Jika seseorang ingin mengubah tingkah laku yang tidak diinginkan, maka ia perlu mengubah bahasa lisan dalam pikirannya (Pilecki \& McKay, 2012; Yovel, 2009). Di Indonesia, ada gagasan yang menyatakan bahwa teknik cognitive defusion dapat digunakan untuk meningkatkan percaya diri siswa (Saputra \& Prasetiawan, 2018).

Pelaksanaan intervensi dengan menggunakan teknik cognitive defusion menggunakan lima tahap, yaitu rasional, pelatihan defusion, identifikasi pikiran negatif, defusion pikiran negatif, serta evaluasi dan tindak lanjut (Saputra \& Prasetiawan, 2018). Pertama, konselor menyampaikan rasional perlakuan. Pada tahap ini konselor menyampaikan alasan percaya diri siswa perlu ditingkatkan dengan menggunakan konseling teknik cognitive defusion. Kedua, tahap pelatihan defusion dimana 
siswa dilatih untuk sampai pada pemikiran bahwa pikiran negatif relatif terjadi pada setiap individu, tetapi individu perlu berkomitmen bahwa itu semua hanyalah sebuah suara dalam pikiran dan tidak perlu didengarkan atau bahkan dilakukan. Ketiga, identifikasi pikiran negatif, pada tahap ini konselor dan konseli berupaya mengidentifikasi pikiran negatif yang muncul pada diri siswa. Keempat, pelaksanaan defusion pikiran negatif. Pada tahap ini siswa akan belajar untuk menganggap pikiran negatif yang ada pada dirinya hanya sebuah suara dan tidak perlu ditanggapi atau bahkan dilakukan. Tahap kelima adalah evaluasi dan tindak lanjut. Pada tahap terakhir ini konselor berupaya untuk melakukan evaluasi sejauh mana keberhasilan pelaksanaan konseling yang telah dilaksanakan.

Temuan dalam penelitian ini didukung oleh penelitian terdahulu yang pernah dilaksanakan, akan tetapi belum pernah dilaksanakan yang secara khusus menguji konseling teknik cognitive defusion dalam meningkatkan percaya diri siswa. Meskipun demikian, penelitian-penelitian terdahulu yang melibatkan teknik cognitive defusion memiliki karakteristik yang sama dengan penelitian ini, yaitu teknik cognitive defusion mengurangi pikiran disfungsional dengan membantu subjek penelitian sampai pada pemahaman pikiran negatif hanya sebuah pikiran (Masuda et al., 2004). Sebuah penelitian menyimpulkan bahwa teknik cognitive defusion dapat mengurangi pikiran negatif yang diyakini dan emosi-emosi yang mengganggu (Masuda et al., 2004). Teknik cognitive defusion yang diterapkan dalam mengurangi keyakinan terhadap pikiran negatif dirancang untuk mengurangi fungsi pikiran negatif dengan mengubah konteksnya daripada mengubah bentuk, frekuensi, atau sensitivitas situasionalnya. Penelitian tersebut sesuai dengan penelitian ini, yaitu teknik cognitive defusion menekankan pada pengulangan kata-kata acuan diri negatif (repetition of negative selfreferential words) dalam mengurangi ketidaknyamanan dan keyakinan terhadap pikiran negatif.

Penelitian lain menyimpulkan bahwa strategi cognitive defusion dapat digunakan untuk mengurangi pernyataan diri negatif (Healy et al., 2008). Subjek dalam penelitian ditugaskan sebagai salah satu dari tiga kondisi eksperimen, yaitu pro-defusion, anti-defusion, dan netral. Temuan penelitian menyarankan menggunakan strategi cognitive defusion dalam mengatasi psikologis negatif. Penelitian tersebut memiliki persamaan dengan penelitian ini, yaitu penerapan teknik cognitive defusion mengubah konteks pernyataan diri negatif dalam menangani perilaku bermasalah.

Sebuah hasil penelitian lain menyimpulkan bahwa teknik cognitive defusion dapat menimbulkan perbaikan jangka panjang yang menggeneralisasi di luar pola pikir negatif yang ditargetkan (Masuda et al., 2009). Bahkan teknik cognitive defusion dapat diterapkan untuk individu yang memiliki pola pikir negatif yang sangat menyedihkan. Penelitian tersebut memiliki persamaan dengan penelitian ini, yaitu menekankan pada pengulangan kata-kata dari pikiran diri negatif (repeating a single word version of a negative self-referential thought) untuk menurunkan ketidaknyamanan dan keyakinan terhadap pikiran negatif tersebut.

Teknik cognitive defusion memiliki pengaruh yang signifikan terhadap psychological distress, dysphoria, dan harga diri yang rendah (Hinton \& Gaynor, 2010). Prosedur cognitive defusion dalam penelitian tersebut mengubah cara seseorang berhubungan dengan pikiran-pikiran negatif tanpa menantang dan mengubah isinya. Prosedur ini dapat mempromosikan fleksibilitas psikologis yang merupakan komponen kunci model $A C T$. Sama halnya dengan penelitian ini, salah satu tujuan utama penerapan teknik cognitive defusion adalah tercapainya fleksibilitas psikologis. Fleksibilitas psikologis adalah kemampuan untuk menyadari dan memberi perhatian terhadap pengalaman yang hadir dan bertingkah laku sesuai nilai-nilai tujuan individu (Harris, 2006).

Teknik cognitive defusion mampu membantu siswa mengatasi kecemasan sosial yang tinggi (Kishita, Muto, Ohtsuki, \& Barnes-Holmes, 2014). Teknik cognitive defusion yang diterapkan dalam mengatasi kecemasan sosial dirancang agar subjek penelitian mengidentifikasi pikiran disfungsional yang menyebabkan kecemasan sosial sebagai pikiran target. Teknik cognitive defusion melatih subjek penelitian agar mampu memahami bahwa pikiran negatif hanya sebatas pikiran negatif dan tidak berpengaruh terhadap perilaku. Penelitian tersebut memiliki persamaan dengan penelitian ini, yaitu penerapan teknik cognitive defusion melatih subjek penelitian sampai pada pemahaman bahwa pikiran negatif hanya sebuah suara dan tidak berpengaruh terhadap perilaku. 
Sebuah penelitian yang menguji dampak teknik cognitive defusion terhadap individu yang memiliki citra tubuh negatif menunjukkan bahwa teknik cognitive defusion berpotensi diaplikasikan pada individu yang memiliki pikiran negatif terhadap bentuk tubuhnya (Mandavia et al., 2015). Penelitian tersebut memiliki persamaan dengan penelitian ini, yaitu berfokus pada penerapan pengulangan kata-kata (word repeating) dari pikiran target sebagai pemicu perilaku bermasalah.

Melalui pemaparan di atas, dapat ditarik kesimpulan bahwa penelitian-penelitian terdahulu dengan tujuan-tujuan penelitian yang beragam menunjukkan penerapan teknik cognitive defusion mampu memberikan hasil yang signifikan dalam mengatasi perilaku bermasalah. Hal ini tentunya menjadi kajian yang menarik bagi para ahli dan praktisi bimbingan dan konseling untuk mengimplementasikan teknik cognitive defusion, sehingga konselor sebagai praktisi dapat terbantu dalam upayanya meningkatkan percaya diri siswa.

\section{SIMPULAN}

Temuan penelitian menunjukkan terdapat kenaikan tingkat percaya diri siswa yang signifikan antara sebelum dan sesudah diberikan intervensi dengan konseling teknik cognitive defusion. Kelebihan dari penelitian ini adalah penggunaan strategi konseling yang relatif baru, yaitu konseling teknik cognitive defusion dalam meningkatkan percaya diri siswa. Konselor seyogyanya merujuk dan menerapkan teknik cognitive defusion dalam upayanya meningkatkan percaya diri siswa. Selain itu, kerja sama yang intensif dengan berbagai lembaga seyogyanya dilakukan untuk mendesiminasikan hasil penelitian ini agar konselor secara lebih luas mampu mengenal dan menerapkan model konseling teknik cognitive defusion untuk meningkatkan percaya diri siswa. Terlepas dari berbagai keunggulan yang telah disebutkan, penelitian ini masih memiliki kelemahan. Kelemahan tersebut terletak pada desain penelitiannya yang terbatas pada penelitian pre-experimental design dengan menggunakan one group pre-test post-test design. Sehingga penelitian ini merekomendasikan penelitian selanjutnya untuk merancang penelitian dengan meningkatkan validitas internalnya.

\section{DAFTAR RUJUKAN}

Afiatin, T., \& Martaniah, S. M. (1998). Peningkatan Kepercayaan Diri Remaja Melalui Konseling Kelompok. Psikologika: Jurnal Pemikiran dan Penelitian Psikologi, 3(6), 66-79.

Al-Hebaish, S. M. (2012). The Correlation between General Self-confidence and Academic Achievement in The Oral Presentation Course. Theory and Practice in Language Studies, 2(1), 60-65. https://doi.org/10.4304/tpls.2.1.60 65

Amilin, A. (2016). The Role of Self-confidence in Moderating The Effect of Emotional Intelligence on Accountants' Career Development: An Indonesian Evidence. International Journal of Economic Perspectives, 10(1), 161-170.

Bach, P. A., \& Moran, D. J. (2008). ACT in Practice: Case Conceptualization in Acceptance and Commitment Therapy. New Harbinger Publications.

Fiorentika, K. F., Santoso, D. B., \& Simon, I. M. (2016). Keefektifan Teknik Self-instruction untuk Meningkatkan Kepercayaan Diri Siswa SMP. Jurnal Kajian Bimbingan dan Konseling, 1(3), 104-111. https://doi.org/10.17977/um001v1i32016p104

Forman, E. M., Herbert, J. D., Moitra, E., Yeomans, P. D., \& Geller, P. A. (2007). A Randomized Controlled Effectiveness Trial of Acceptance and Commitment Therapy and Cognitive Therapy for Anxiety and Depression. Behavior Modification, 31(6), 772-799.

Fung, K. (2015). Acceptance and Commitment Therapy: Western Adoption of Buddhist Tenets? Transcultural Psychiatry, 52(4), 561-576.

Gatz, J., \& Kelly, A. M. (2017). Afterschool School Triathlon Training for 11-to 14-year Old Girls: Influences on Academic Motivation and Achievement. Health Education Journal, 77(2), 156168. 
Hakim, T. (2002). Mengatasi Rasa Tidak Percaya Diri. Jakarta: Puspa Swara.

Hankin, S. (2005). Pede Abis!: Strategi untuk Meningkatkan Rasa Percaya Diri. Gramedia Pustaka Utama.

Harris, R. (2006). Embracing Your Demons: An Overview of Acceptance and Commitment Therapy. Psychotherapy in Australia, 12(4), 2-8.

Hayes, S. C., Luoma, J. B., Bond, F. W., Masuda, A., \& Lillis, J. (2006). Acceptance and Commitment Therapy: Model, Processes and Outcomes. Behaviour Research and Therapy, 44(1), 1-25.

Healy, H.-A., Barnes-Holmes, Y., Barnes-Holmes, D., Keogh, C., Luciano, C., \& Wilson, K. (2008). An Experimental Test of A Cognitive Defusion Exercise: Coping with Negative and Positive Self-statements. The Psychological Record, 58(4), 623-640.

Hinton, M. J., \& Gaynor, S. T. (2010). Cognitive Defusion for Psychological Distress, Dysphoria, and Low Self-esteem: A Randomized Technique Evaluation Trial of Vocalizing Strategies. International Journal of Behavioral Consultation and Therapy, 6(3), 164-185. https://doi. org $/ 10.1037 / \mathrm{h} 0100906$

Ifdil, I., Denich, A. U., \& Ilyas, A. (2017). Hubungan Body Image dengan Kepercayaan Diri Remaja Putri. Jurnal Kajian Bimbingan dan Konseling, 2(3), 107-113. https://doi.org/10.17977/ um001v2i32017p107

Imro'atun, S. (2017). Keefektifan Layanan Konseling Kelompok untuk Meningkatkan Kepercayaan Diri Siswa Sekolah Menengah Pertama. Jurnal Kajian Bimbingan dan Konseling, 2(2), 50-57. https://doi.org/10.17977/um001v2i22017p050

Kishita, N., Muto, T., Ohtsuki, T., \& Barnes-Holmes, D. (2014). Measuring the Effect of Cognitive Defusion Using The Implicit Relational Assessment Procedure: An Experimental Analysis with A Highly Socially Anxious Sample. Journal of Contextual Behavioral Science, 3(1), 8-15.

Lie, A. (2008). Menjadi Orang Tua Bijak. 101 Cara Menumbuhkan Percaya Diri pada Anak. Jakarta: Gramedia Sugiyono.

Mandavia, A., Masuda, A., Moore, M., Mendoza, H., Donati, M. R., \& Cohen, L. L. (2015). The Application of A Cognitive Defusion Technique to Negative Body Image Thoughts: A Preliminary Analogue Investigation. Journal of Contextual Behavioral Science, 4(2), 86-95.

Markanday, S., Data-Franco, J., Dyson, L., Murrant, S., Arbuckle, C., McGillvray, J., \& Berk, M. (2012). Acceptance and Commitment Therapy for Treatment-resistant Depression. Aust NZJ Psychiatry, 46(12), 1198-1199.

Mastur, M., Sugiharto, D. Y. P., \& Sukiman, S. (2012). Konseling Kelompok dengan Teknik Restrukturisasi Kognitif untuk Meningkatkan Kepercayaan Diri Siswa. Jurnal Bimbingan Konseling, 1(2), 74-80.

Masuda, A., Feinstein, A. B., Wendell, J. W., \& Sheehan, S. T. (2010). Cognitive Defusion Versus Thought Distraction: A Clinical Rationale, Training, and Experiential Exercise in Altering Psychological Impacts of Negative Self-referential Thoughts. Behavior Modification, 34(6), 520-538.

Masuda, A., Hayes, S. C., Sackett, C. F., \& Twohig, M. P. (2004). Cognitive Defusion and Selfrelevant Negative Thoughts: Examining The Impact of A Ninety Year Old Technique. Behaviour Research and Therapy, 42(4), 477-485.

Masuda, A., Hayes, S. C., Twohig, M. P., Drossel, C., Lillis, J., \& Washio, Y. (2009). A Parametric Study of Cognitive Defusion and The Believability and Discomfort of Negative Self-relevant Thoughts. Behavior Modification, 33(2), 250-262.

Perry, M. (2005). Confidence Boosters: Pendongkrak Kepercayaan Diri. Esensi. Jakarta.

Pilecki, B. C., \& McKay, D. (2012). An Experimental Investigation of Cognitive Defusion. The Psychological Record, 62(1), 19-40. 
Proude, E. M., Conigrave, K. M., \& Haber, P. S. (2006). Effectiveness of Skills-based Training Using the Drink-less Package to Increase Family Practitioner Confidence in Intervening for Alcohol Use Disorders. BMC Medical Education, 6. https://doi.org/10.1186/1472-6920-6-8

Ruiz, F. J. (2012). Acceptance and Commitment Therapy Versus Traditional Cognitive Behavioral Therapy: A Systematic Review and Meta-analysis of Current Empirical Evidence. International Journal of Psychology and Psychological Therapy, 12(3), 333-357.

Saputra, W. N. E., \& Prasetiawan, H. (2018). Model Konseling Cognitive Defusion untuk Meningkatkan Percaya Diri Siswa. Yogyakarta: K-Media.

Siska, Sudardjo, \& Purnamaningsih, E. H. (2003). Kepercayaan Diri dan Kecemasan Komunikasi Interpersonal pada Mahasiswa. Jurnal Psikologi, 30(2), 67-71.

Stankov, L., Morony, S., \& Lee, Y. P. (2014). Confidence: The Best Non-cognitive Predictor of Academic Achievement? Educational Psychology, 34(1), 9-28.

Strosahl, K. D., Robinson, P. J., \& Gustavsson, T. (2012). Brief Interventions for Radical Change: Principles and Practice of Focused Acceptance and Commitment Therapy. New Harbinger Publications.

Suhardita, K. (2011). Efektivitas Penggunaan Teknik Permainan dalam Bimbingan Kelompok untuk Meningkatkan Kepercayaan Diri Siswa (Penelitian Quasi Eksperimen pada Sekolah Menengah Atas Laboratorium (Percontohan) UPI Bandung Tahun Ajaran 2010/2011). Jurnal Penelitian Pendidikan, 11(1), 127-138. Diambil dari http://jurnal.upi.edu/file/12-Kadek_Suhardita.pdf

Tatuh, M. C. (2012). Hubungan Antara Kepercayaan Diri dengan Motivasi Berprestasi pada Siswa di SMA Negeri 1 Salatiga. Program Studi Psikologi FPSI-UKSW.

Tavani, C. M., \& Losh, S. C. (2003). Motivation, Self-confidence, and Expectations as Predictors of The Academic Performances Among Our High School Students. Child Study Journal, 33(3), $141-152$.

Wahyuni, S. (2014). Hubungan Antara Kepercayaan Diri dengan Kecemasan Berbicara di Depan Umum pada Mahasiswa Psikologi. Jurnal. UNMUL: Psikologi, 2(1), 50-64.

Yovel, I. (2009). Acceptance and Commitment Therapy and The New Generation of Cognitive Behavioral Treatments. Israel Journal of Psychiatry and Related Sciences, 46(4), 304-309. 